\title{
RESIST, COMPLY OR WORKAROUND? AN EXAMINATION OF DIFFERENT FACETS OF USER ENGAGEMENT WITH INFORMATION SYSTEMS
}

${ }^{1}$ Ferneley, Elaine, H., Informatics Research Institute, University of Salford, Ashworth Building, The Crescent, Salford, Manchester, UK, E.Ferneley@salford.ac.uk

Sobreperez, Polly, Informatics Research Institute, University of Salford, Ashworth Building, The Crescent, Salford, Manchester, UK, P.Sobreperez@salford.ac.uk

${ }^{1}$ Contact Author 


\title{
RESIST, COMPLY OR WORKAROUND? AN EXAMINATION OF DIFFERENT FACETS OF USER ENGAGEMENT WITH INFORMATION SYSTEMS
}

\begin{abstract}
This paper provides a summary of studies of user resistance to Information Technology (IT) and identifies workaround activity as an understudied and distinct, but related, phenomenon. Previous categorizations of resistance have largely failed to address the relationships between the motivations for divergences from procedure and the associated workaround activity. This paper develops a composite model of resistance/workaround derived from two case study sites. We find four key antecedent conditions derived from both positive and negative resistance rationales and identify associations and links to various resultant workaround behaviours and provide supporting Chains of Evidence from two case studies.
\end{abstract}

Keywords: Resistance, Compliance, Workaround, Chains of Evidence, Case Study Research.

\section{INTRODUCTION}

The successful implementation of various types of Information Technology (IT) is seen as a prerequisite for enhancing the competitiveness and productivity of an organization. Yet successful implementation remains elusive with many theories and frameworks emerging intent on enlightening designers and developers regarding the sources of implementation problems and specifically user resistance to new implementations (Hirschheim and Newman, 1988, Davison et al., 2004, Markus, 1983). The literature has been dominated by negative connotations associated with resistance, often concluding that it is undesirable and detrimental to an implementation's success (Schein, 1988, Kossek et al., 1994); that it is a product of employees’ opposition to control and domination (Cook and Brown, 1999); and that it inhibits 
strategic change (Ansof, 1988). However, resistance is emerging as a more complex phenomenon than previously thought and need not always be viewed negatively (Hirschheim and Newman, 1988, Lapointe and Rivard, 2005). Indeed resistance may be a manifestation of user unease with a flawed system (Mumford et al., 1978, Marakas and Hornik, 1996, Keen, 1981, Hirschheim and Klein, 1994) or may even be regarded as functionally useful (Markus, 1983). For example whilst deviation in a non-managerially prescribed manner is typically regarded as resistance or recalcitrance, on closer inspection, this type of behaviour may also be revealed as positive or supportive and undertaken in order to overcoming the shortcomings of new technology which, for example, is genuinely unable to sustain, monitor or track actual working practices at the same time as allowing employees to work co-operatively or flexibly (Bain and Taylor, 2000). Where a mismatch occurs between the expectations of technology and actual working practice, employees may implement a 'workaround' by deviating from set procedures. This notion of workaround is defined by Kobayashi et al (2005) as: 'informal temporary practices for handling exceptions to workflow'. Under such circumstances the success of industrial operations necessitates that the normative mechanisms of surveillance and control of processes are 'deceived' by the operators in what is describable as a 'Trompe L'Oeil' in order to cover for the inadequacies of the computerized information system (Sobreperez et al., 2005).

We posit that the implementation of workarounds may be for more complex reasons than the existing literature on user resistance proposes. If a key objective for management is 'to reduce the negative divergences and exploit the positive divergences which individuals make' (Sewell and Wilkinson, 1992) then we require a deeper understanding of the rationale behind positive and negative divergences. Using case study research we attempt to augment the literature on user resistance by proposing a model focusing on the manifestations of 
workaround behaviours as the result of interactions between several antecedents drawn from both the social and technical domains.

The paper makes the following contributions, firstly it examines current models of resistance and attempts to more clearly identify the concept of workaround as a related but different, separate and subsequent phenomenon. The model extends previous resistance models and provides an alternative theoretical basis for explaining and predicting acceptance of information systems in certain types of environments. Secondly the relationship between resistance models and workarounds is considered in the context of current resistance models, many of which hint at but do not explore occurrences of workarounds. In addition, two case studies are analysed, which enrich and enlighten current thinking in this area and exemplify the various types of workaround classification and how they differ from previous resistance models. The paper identifies workarounds as an additional dimension to studies of resistance and a further strand to the discussions on the limitations of information systems in particular contexts.

In the following sections of the paper we assess existing models of resistance/workaround and identify six basic categories: compliance, positive resistance, negative resistance, harmless workarounds, hindrance workarounds and essential workarounds. Using data from two case studies we verify the presence of the basic constructs and use analytical induction to uncover new constructs, relationships and boundaries that enriched our understanding of the relationship between resistance, be it positive or negative, and the resultant workaround behaviours. The paper concludes by proposing a two phased theoretical framework for analysing the act of resistance and the resultant workaround behaviour. 


\section{BACKGROUND AND INITIAL FRAMEWORK}

The notion of the compliant user, interacting with a system for the intended purpose in the intended way controlled through cultural and technical mechanisms has been presented in some literature as an approach that has been largely successful (Fernie and Metcalf, 1998; Sewell and Wilkinson, 1992). However, others argue that resistance is inevitable and a number of authors have proposed theoretical explanations of how and why resistance occurs (Folger and Skarlicki, 1999; Jermier et al. 1994; Lyytinen and Hirschheim, 1987). In an information systems context, workforce resistance has largely been viewed as the negative behaviour of system users which may prevent system designers achieving their objectives, or affect the success of system implementation, and may be symptomatic of the culture and politics of the organisation as a whole (Markus, 1983). For example, Martinko et al (1996) propose a model based on attribution theory that suggests that an individual user displays resistance or acceptance of a new IT system dependent upon attitudes and beliefs formed by their previous experiences of new systems' implementation. Lapointe and Rivard (2005), Rosenthal (2004), Webb and Palmer (1998) and Joshi (1991) have all developed multilevel models of user resistance showing that resistance can take place at the individual, group or organizational level. Lapointe and Rivard's model suggests that resistance can manifest itself as passive, active or aggressive resistance, whilst Rosenthal (2004) proposes that workers will manipulate systems to satisfy their self defined interests. Webb and Palmer (1998) posit that supervisors may collude in resistant behaviours whilst Joshi (1991) suggests that users will resist if they perceive inequity at individual, peer group or organisational level. Marakas and Hornik (1996) propose that a user may comply with a system that they know to be flawed without highlighting said flaws. They suggest that whilst the user may be regarded as compliant with the information system they are also exhibiting resistance to their employment; they are not acting in the best interests of the organisation by failing to highlight 
the system's shortcomings. Furthering this notion of façade, Prasad and Prasad (2000) propose that resistance takes place at a low level continuously throughout the organization. Additionally, some have pointed out that there may be good organisational reasons for resisting poorly designed or implemented systems, and that this 'positive resistance' can be used by developers to improve future versions (Mumford, 1976; Hirschheim and Newman 1988). The various resistant behaviours highlighted by these models show that resistance can exist in various forms, from lack of co-operation to deliberate sabotage and several authors have attempted to adopt classification schemes (c.f. Joshi, 1991, Prasad and Prasad, 2000, Marakas and Hornik, 1996, Lapointe and Rivard, 2005, Waddell and Sohal, 1998).

Kobayashi et al. (2005) and Petrides et al (2004) have proposed an alternative scenario in which users do engage with the system but fail to conform to the prescribed 'rules of engagement', they define this as the notion of workaround. Indeed other authors, whilst they do not use the term workaround explicitly, provide examples of workaround behaviours that emerge following system rejection or resistance. For example, as highlighted by Button et al. (2003) and Lankshear and Mason (2001) in environments where individuals have insufficient data, unsuitable access or enforced proceduralisation they may compensate by creating idiosyncratic methods of data collection, data management or working practice, in effect overcoming hindrances or ensuring essential task completion.

Hence, revisiting the literature, whilst authors use classification schemes which focus on the initial rejection rationale (e.g. positive versus negative resistance) we propose that this nomenclature is reconsidered and that a revised taxonomy may be more appropriate which includes the notion of subsequent workaround activities. Drawing from the literature, an initial taxonomy is presented in table 1, each category is then reviewed in turn.

\begin{tabular}{|l|l|}
\hline Category & Explanation/Definition \\
\hline Compliance & $\begin{array}{l}\text { The user interacts with the system in the prescribed manner (Fernie and } \\
\text { Metcalf, 1998; Sewell and Wilkinson, 1992) }\end{array}$ \\
\hline
\end{tabular}




\begin{tabular}{|l|l|l|}
\hline Resistance & \multicolumn{2}{l}{$\begin{array}{l}\text { Opposition, challenge or disruption to processes or initiatives (Jermier et } \\
\text { al, 1994; Folger and Skarlicki, 1999) }\end{array}$} \\
\hline & $\begin{array}{l}\text { Negative } \\
\text { Resistance }\end{array}$ & $\begin{array}{l}\text { The rationale is to oppose or deceive (Marakas and Hornik } \\
\text { 1996; Fernie and Metcalf, 1998; Webb and Palmer, 1998; } \\
\text { Bain and Taylor, 2000; Callaghan and Thompson, 2001; } \\
\text { Rosenthal, 2004; Lapointe and Rivard, 2005) }\end{array}$ \\
\hline \multirow{2}{*}{$\begin{array}{l}\text { Porkaround } \\
\text { Resistance }\end{array}$} & $\begin{array}{l}\text { The action ensuing from resistance (Kobayashi et al 2005; Petrides et al, } \\
\text { et al, 2003) }\end{array}$ \\
\hline & $\begin{array}{l}\text { Hindrance } \\
\text { Workaround }\end{array}$ & $\begin{array}{l}\text { The workaround is undertaken to circumvent system } \\
\text { procedures or process perceived to be too time consuming, } \\
\text { onerous or difficult. (Prasad and Prasad, 2000; Lankshear } \\
\text { and Mason 2001) }\end{array}$ \\
\hline & $\begin{array}{l}\text { Harmless } \\
\text { Workaround }\end{array}$ & $\begin{array}{l}\text { The workaround does not significantly affect workflow or } \\
\text { the accuracy of captured data (Button et al 2003; Lapointe } \\
\text { and Rivard, 2005) }\end{array}$ \\
\hline & $\begin{array}{l}\text { Essential } \\
\text { Workaround }\end{array}$ & $\begin{array}{l}\text { The workaround is essential in order to complete the task } \\
\text { at hand (Lankshear and Mason 2001; Kobayashi, 2005) }\end{array}$ \\
\hline
\end{tabular}

\section{Table 1: Initial Compliance/Resistance/Workaround Categories}

Firstly, compliance assumes that the user interacts with the system in the prescribed manner, although it has been argued that total compliance is unlikely and that a low level of resistance is inevitable (Prasad and Prasad, 2000). Secondly, resistance whereby the user opposes or challenges the system prescribed view, this can be subdivided into positive or negative perspectives. Negative resistance is typically manifest by behaviours (or workarounds) such as: physical sabotage; deliberate entering of incorrect data; deliberate omission of auditable steps in procedures and 'fiddling' of time targets and production level data (Fernie and Metcalf, 1998, Callaghan and Thompson, 2001). Positive resistance is typically manifest by behaviours (or workarounds) such as deviation from procedure or covert co-operative working and seeks to support or improve working practices. 
Revisiting the literature, this notion of workaround activity can be subdivided into three strands. Hindrance workarounds occur when the use of the system is viewed as too time consuming, onerous, or difficult. There is no specific malcontent associated with the action, rather the worker perceives that the system is burdensome, they may not see the point or relevance of the data that they are entering and therefore partially enter data, enter approximate data or fail to fully comply with procedure. For example consider Lankshear and Mason's (2001) study on situations in the pressurised working environment of a maternity ward where users did not appreciate the ramifications to the dataset of circumventing various data capture processes and failed to comply with procedures which did not allow the recording of group decision making, or support their perception of the situation.

As further illustration, in Timmons's (2003) study of patient care plans in UK hospitals, a monthly audit found that according to computer records, one ward had only six patients. Nursing staff had failed to enter and update patient information seeing accurate data entry as a hindrance and as low priority in comparison to their 'real' job of nursing patients.

Harmless workaround occurs when users do not use the system in the prescribed manner but their workarounds do not affect workflow or the accuracy of captured data. Examples of this can be found in Button et al's (2003) multifaceted study of workflow management systems, as illustrated by workers undertaking predictive processing, the job was still completed and the required management data was still captured within the new system, hence their predictive processing activity was harmless and was viewed by both operators and management to be harmless.

Essential workarounds are those regarded as critical or vital by the workforce, even though they do not follow prescribed procedures (Kobayashi et al., 2005, Button et al., 2003). Consider the type of behaviour exhibited by 'professionals' who are requesting equipment or dynamically recording emergency incidents and procedures (Kobayashi et al. 2005; Wilson, 
2002). The workaround behaviours undertaken are seen by the professionals as essential to the safety of lives, property or situations and are not simply motivated by the protection or defence of professional judgement, status or position (Kobayashi et al, 2005; Lankshear and Mason, 2001).

In the following section we seek to explore the compliance/resistance/workaround relationships from the perspective of the participants in two highly operationally controlled case studies

\section{THE CASE STUDIES AND RESEARCH METHOD}

There is increasing recognition of the importance of studying technology in use to inform the development of new technology, indeed there is argument that relatively few analyses look at what is actually 'done' with technology, as (Orr, 1996) states: '....this is the main problem with all the literature. It is not well grounded in analysis of work practice, so its presumptions and prescriptions of what is to be done are not based on what is done and what needs to be done, on the reality of the job, the tasks to be accomplished'.

In the context of this research Orr's statement, whilst 10 years old, is particularly apt as we aim to examine the phenomenon of user workarounds - the actual reality of the task at hand rather than the prescribed working processes.

The research has adopted the interpretive paradigm as it considers not only the influence of the implemented technology but also the broader context, including the multiple relevant social groups and the wider environment. (Walsham, 1993, Klein and Myers, 1999). As stated by Walsham (1993), interpretive research methods are 'aimed at producing an understanding of the context of the information system, and the process whereby the information systems influences, and is influenced by the context' (Walsham, 1993, p. 4-5). 
In order to analyse the actuality of workarounds this research draws deductively from existing literature and then, using an inductive analytical approach, the initial conceptual framework is further explored and refined at two case study sites, providing a 'causal description' of the manifestations of workarounds and their impact. To achieve this we adopt an interactive model of data analysis the four components of which (data collection, data reduction, data display and conclusion drawing/verification) are conducted continually and iteratively rather than as a linear process (Miles and Huberman, 1994). As Wolcott (1982) states, there is merit in allowing a conceptual framework to emerge during the course of study, indeed this facilitates an open minded approach to analysis, although it is 'impossible to embark upon research without some idea of what one is looking for and foolish not to make the quest explicit' (Wolcott, 1982; p.157). Therefore, our initial set of analytical categories were derived deductively from the existing literature (table 1) and subsequent primary data collection, reduction, display and analysis was then conducted inductively from the two case studies allowing a richer framework to evolve and be tested for plausibility across datasets.

\section{Case Studies}

The first case study is within the service industry and in the paper is referred to as GarmentCo whilst the second is in the public sector - a UK regional Fire Service. In both cases the domain under study was a highly operationally controlled environment, clear preset routines, procedures and practices were in place with operational staff given limited discretion or autonomy over work activities or decision making. In the environments under study the rationale for such control was that workers would have limited opportunity to deviate from prescribed routines.

The research at each case study site started in July 2003 and is ongoing. Research so far has included participant observation based on watching and listening, individual and group semi- 
structured interviewing and document analysis. Interviews typically began with generic questions allowing users to express their opinions on the use of technology before moving to more specific questioning to ensure that data from each case covered similar areas thus allowing cross-case comparison, data collection ceased at the point of data saturation (Miles and Huberman, 1994).

At GarmentCo 15 semi-structured interviews of between 20 minutes and 1 hour have taken place with 3 managers, 2 supervisors and 10 operators. These individuals were chosen as they were longer serving employees and had performed a variety of tasks within the company. In addition participant observation was undertaken for approximately 20 hours during which time extensive free format field notes were taken and direct observation of resistance and subsequent workaround activity occurred.

At the Fire Service 14 taped individual semi-structured interviews of between 40 minutes and 1.5 hours have been conducted with 3 senior managers, 8 middle managers and 3 data analysis personnel (all ex. Fire Officers). The managers were chosen due to their long service records and the diverse range of roles that they occupied whilst the data analysis personnel interviewed represented staff who were responsible for collating and distributing the specific data under analysis. Additionally, 24 taped group semi-structured interviews of between 1.5 and 3 hours were conducted with groups of between 8 and 15 Fire Officers. During these group interviews demonstrations of IT workarounds were provided, allowing direct observation of workaround activity. Furthermore, as the Fire Service operates a single entry point system whereby all personnel (except administrators which account for c.15\% of the Service’s personnel) must enter the Fire Service as a Fire Officer and then work their way up through the organisational structure all of the 14 more senior personnel who were interviewed individually had at some time been Fire Officers. Therefore references to historical 
workaround practices were cross validated with current Fire Officers in the group interviews to identify if such workarounds still existed or had changed.

\section{Case Study 1: Service Industry - GarmentCo}

GarmentCo engages in the hire of men's formal clothing including jackets, trousers, waistcoats, shirts, ties and other accessories. These components are put together in the required sizes and styles to form an outfit according to the specifications of the customer. They are then distributed to the retail branch through which they were ordered and, when subsequently returned, are checked, brushed, dry-cleaned or laundered as appropriate, and returned to stock. When an order has been created, an order ticket is printed on the shop floor containing a barcode and all the component garment details. The user uses a personal login and scans the order barcode to assign garments to orders. The ticket follows an automatic conveyancing system around the factory which serves to transport the outfit through areas which contain individual items of clothing such as jackets, trousers, shirts, waistcoats, shoes, hats, and accessories. The accompanying ticket shows which style and size to pick from each area. Each shop floor zone has at least one operative selecting garments, scanning the barcode and attaching them to the appropriate order. The outfit continues around the shopfloor until all items are picked and then it is despatched. The system aims to process 30 orders per hour. The collected data is used for target setting, trend analysis, stock renewals and resource planning purposes.

\section{Case Study 2: Public Sector - Regional Fire Service}

The regional Fire Service case study is concerned with the mobilisation of fire engines to incidents and the reporting of said incidents. As incidents are reported to the Fire Service a 
centralised control office records initial incident details including incident location, who has reported the incident, Fire Service personnel and fire engines that are dispatched immediately and subsequently, the route or routes taken by fire engines, dispatch and arrival times and a log of all communications with the deployed Fire Service teams. During and after the incident a detailed electronic report is completed on the incident, the report is semi-structured and any level of Officer can be assigned the responsibility of completing the report. Structured attributes include cause of fire, location within the address, degree and speed of fire spread, number of casualties, other emergence services involved, specific equipment used and arrival and departure times. Free format responses include incident handling strategies and lessons learnt. These reports are collated and summarized by a centralised office that then presents the abstracted results to management who plan the allocation of future human and physical resources from this data. In addition the summarized data is reported to central government who allocate funding and make policy decisions based on the data.

\section{ANALYSIS AND CODING}

The initial categorisation scheme of Compliance, Positive Resistance, Negative Resistance, Harmless Workaround, Hindrance Workaround and Essential Workaround was applied deductively both at the time of data collection and by retrospective analysis on the completed transcripts and supporting field notes. Because qualitative data analysis is an open and iterative process applying the initial coding scheme to the case studies resulted in the emergence or induction of a richer coding set as the initial codes were 'extended', 'filled in', 'bridged' and 'surfaced' (Lincoln and Guba, 1985). The case study data was analysed in two stages, within-case analysis and cross-case analysis (Eisenhardt, 1989). 


\section{Within Case Analysis}

Within-case analysis was performed to allow unique patterns to emerge and the researchers to gain a richer understanding of each case study. Individual workaround behaviours were analysed identifying the rationale for deviating from the prescribed process or procedure. Individual instances were then conceptually clustered with different clustering permutations being trialled; the researchers undertook the clustering process independently and then collaboratively. Whilst the individual instances were firstly analysed under the initial categorisation scheme of harmless, hindrance or essential workaround the detailed analysis exposed sub-clusters, for example 'stockpiling', 'inaccurate data entry' and 'retrospective data entry', sub-clusters can be manifestations of more than one type of workaround behaviour (see table 2 for examples drawn from the case studies).

\section{Case Study 1: GarmentCo}

In the GartmentCo case study, workaround practices such as batch processing were observed: "Workers often ... compile several similar orders at once” [Supervisor 1]. Similarly, examples of sub-tasking occurred: "We will break down orders [into subcomponents] to find matches which we can pick together" [Operative 3]. Predictive operating and incorrect job sequencing were also identified for example, using their experience operators would search for common garment sizes although no associated orders were issued. Similarly, “Workers begin to compile the next order which hasn't even reached them yet [as they are informed it is on its way by colleagues]” [Supervisor 1].

Issues of targets were identified. Each operative had a target of how many garments should be picked in an hour or day, these were fairly easily achievable targets and made allowances for anomalies such as stoppages, examples arose where operatives were indolent and 
underperformed: "Targets are set too low and workers slack off when they have reached them" [Supervisor 1] and "there's all sorts of things we can do to get a skive, or make the conveyor stop and get overtime to finish that day's orders” [Operator 4]. In addition: “We often double scan [each others] garments to ensure our [personal] count goes up" [Operative 2], an example of inappropriate targets resulting in stockpiling. Alternatively instances arose where targets were seen as unachievable and operators did not even attempt to meet them: "Some targets are way too high, completely impossible, we don't even try" [Operative 6], their failure to challenge unachievable targets could again be regarded as indolence.

Whilst users, in theory, had no choice but to use the system, in practice they co-opted other users to input data on their behalf. Initial investigations revealed three main reasons for this: buddying: "I'll do some for you as you have a hangover" [Operator 8]; bargaining: "I'll give you some cigs if you do some under my code" [Operator 2]; and bullying "They have to do some under my code or there'll be trouble" [Operator 5].

Researchers also witnessed sabotage "Computer mouse balls have been removed and keyboard keys pulled off" [Operative 5]. These resulted in stoppages and therefore delays in upward reporting, this tended to happen in the late afternoon when targets were met and operators felt they have done enough for the day.

\section{Case Study 2: Fire Service}

In the Fire Service case study reporting on fire incidents was often undertaken retrospectively: "I have to enter the data after the event from what the lads and I can remember, sometimes, if it is the next day, we can't remember details” [Middle Manager 1]. Such collective data generation can be viewed positively: "We work as a unit, as a team, it doesn't matter how it's recorded" [Fire Officer 27], indeed more accurate, validated, data may be captured. However it also provides the opportunity for reporting of errors or mistakes 
to be circumvented: “We sometimes request equipment we 'may' need and then justify it later by describing the incident as though we needed the kit" [Fire Officer 3]. Inaccurate data entry was also witnessed regarding Fire Service speed of response which is timed and measured against government targets. Fire engines have mechanisms for relaying to the control office that they have arrived at an incident. If they are approaching their target arrival time and have yet to arrive it is common for the 'arrived' feedback to be sent to the control office before actual arrival hence the illusion of targets being met is created: "Once we get near the fire, we press the arrived button, to make sure we are within time” [Fire Officer 23] and 'If we are later than target, we 'forget' to press the arrived button, then it has to be done over the phone later." [Fire Officer 16]. Several other instances also occurred where users entered incorrect or poorly specified data into the system, codes were entered because they allowed progression to subsequent parts of the system, or codes were not entered due to indolence, for example: “Once it's logged in, it's logged in for the day, I have never seen anyone log out and back in under their own password” [Middle Manager 2].

Deliberate sabotage of both hardware and software was reported to researchers: "I've brought viruses in from my kid's machine, it takes 2-3 days for the IT guys to come out and remove viruses from the Station's PC” [Fire Officer 26]. These were regarded as 'successful' by fire station personnel as the 2-3 day period taken to get an IT technician to visit a station eliminates the need for report generation for that period of time.

Another issue raised was where Fire Officers ignore or misuse a system which does not allow them the perceived appropriate level of discretion and autonomy, this was reflected in nonuse or inaccurate use of the system: "Each incident requires individual dynamic risk assessment, and there are times when policy is not followed" [Fire Officer 36]; "It [the form] doesn't let you describe what really happened, it's just making the fire fit the form, it isn't an 
accurate account" [Fire Officer 4] and "The report I saw was not for the fire I went to" [Fire Officer 17].

\section{Cross Case Analysis}

Cross-case analysis was undertaken using analytical induction to identify both common themes and unique patterns or behaviours. Abstracting from the individual cases we focussed on the causes, pre-existing conditions or antecedents that generated the resultant behaviours of harmless, hindrance or essential workaround. Our specific interest was in finding the resistance rationale (be it positive or negative) and the antecedent conditions from which that resistance rationale emerged. The derivation of the resultant antecedent conditions is illustrated in table 2, the antecedent conditions being 'Enforced Proceduralisation', 'Discipline', 'Non-engagement with the System' and 'Organisational and Personnel Issues', (Sobreperez et al. 2005).

The antecedent condition 'Enforced Proceduralisation' assumes chronological or consecutive job sequencing and that each task is carried out by only one operator from start to finish. The workarounds occur when the application of the model is placed outside and before its enactment (Dourish et al., 1996). For example, many systems do not recognise that operators provide cooperative support that may involve logging onto someone else's system, even though this may not be a part of their formal work description. Thus, it may be that abstracting from the case studies, 'Enforced Proceduralisation' provides the underpinning rationale for negative resistance through compliance of superiors in harmless workaround acts such as incorrect job sequencing and subtasking and essential workaround acts such as

retrospective data entry. Furthermore, 'Enforced Proceduralisation' provides the underpinning rationale for positive resistance in two forms. Firstly, avoidance of inappropriate procedures which may result in workaround actions including predictive 
operating and sub-tasking. Secondly, the inhibition of co-operative working restricting groups, teams and organisations ability to generate collaborative data resulting in essential workaround actions of retrospective data entry and collective data generation. For illustration consider the Fire Service case study where lack of support for co-operative working emerged. The incident recording system assumed a single Fire Officer recorded the incident individually whilst in fact several Fire Officers would usually contribute to the generation of an incident report giving different perspectives and effectively generating a multiple authored report.

Our second identified antecedent condition is derived from the dichotomy between technologically managed bureaucratic control and the social structures inherent in the workplace, we named this antecedent condition 'Discipline'. Whilst Fernie and Metcalf (1998) argue that technological intervention can be the epitome of work surveillance we concur with other authors (e.g. (Callaghan and Thompson, 2001, Lankshear et al., 2001) who have argued that such a view is simplistic and ignores the human tendency to reject close control and authority. In the case studies the 'Discipline' imposed by surveillance and target setting led to negative resistance in three forms: deception, target avoidance and acquisition of personal and social space. The resultant behaviours included sabotage, indolence, buddying, bargaining and bullying. In the case studies, deception was commonplace, for example easily achievable targets at GarmentCo resulted in operators slackening off when targets were achieved and creating diversionary workarounds to give themselves personal or social space, such workarounds, manifest as buddying, bargaining and bullying were either categorised as harmless in that the underlying data required by management was not damaged, or as hindrance workarounds as, for example, the workforce perceived the rigour imposed by the system hindered their ability to interact with their colleagues. However, it 
may be noted that from a social perspective such activities may not necessarily be regarded as harmless.

Similarly in the Fire Service unachievable targets regarding incident arrival time resulted in system deception For example, consider a group of Fire Officers reporting on a burnt out stolen car incident, they may record the probable cause of the incident as: 'spontaneous combustion' (i.e. it caught fire having rolled over or having hit an obstacle) or 'arson'. If they record it as 'spontaneous combustion' they have to engage in minimal liaison with the Police however if they report it as 'arson' then more extensive collaboration with the Police is required. It is commonly accepted across all levels of the Fire Service that the actual arson figures are much higher than those recorded and no pressure is brought to bear to ensure more accurate reporting. Yet, the drop in arson rates is also reported to the general public in percentage terms. This example of inaccurate data entry, as an enactment of a hindrance workaround, spans a range of issues including deception and compliance of superiors .

Our third identified antecedent condition is derived from the refusal of users to fully engage with the system or correctly identify themselves to it, we refer to this as 'Non-engagement with the System'. Many systems are unable to employ and utilise the flexibility common to human interactions and indeed on occasion they actively inhibit such skills and only work well when circumvented by users. This may be a feature of information systems in general which, it has been argued, suffer from the imposition of procedural plans and may not allow for, anticipate, or support situated actions such as altering, sharing, executing and correcting activities in a co-operative manner (Suchman, 1987). In the case studies 'Non-engagement with the System' provided the rationale for negative resistance through deception, avoidance of time overhead and compliance of superiors and for both positive and negative resistance in the form of lack of understanding. Illustrative behaviours from the case studies include at 
GartmentCo the use of other operatives' user IDs due to indolence, and in the Fire Service, inaccurate data entry to bypass the time overhead involved in thorough and accurate reporting. In addition there was a lack of understanding about the usage of data generated by the system: “Don't know what they use it for, don't care” [Operative 3], and the avoidance of the time overheads: "it's not worth the time to log out and back in again, it takes ages" [Operator 3]. Compliance of Superiors in these workaround strategies was also apparent particularly at supervisory level, their attitude being that data capture was a secondary, or even trivial consideration, did not matter and hindered workflow: "we are not interested as long as the job gets done” [Supervisor 1].

Our fourth antecedent condition is derived from the importance of social relations in the workplace and is referred to as 'Organisational and Personnel Issues'. Studies have shown that the emergence of new technology may reduce traditional time-wasting techniques, but alternative ways of reappropriating time are invented by workers who wish for a break (Bain and Taylor, 2000, Lankshear et al., 2001, Webb and Palmer, 1998). In the case studies 'Organisational and Personnel Issues' provided the underlying rationale for negative resistance in the form of collective resistance and peer pressure and for positive resistance in the form of the exercising of professional judgement and overcoming a lack of opportunity to record or provide an holistic overview. Illustrations from the case studies include a number of examples in the Fire Service where workplace culture was significant and influenced system use: "You get the micky taken out of you if you're too keen to fill in the forms .. there's no point .. you only get laughed at" [Fire Officer 12]. Collective resistance against the system also occurred: "There is active discouragement of IT use amongst the lads" [Fire Officer 32] and “They [senior officers] don't want us to use it, they think we'll mess it up" [Fire Officer 28]. There was also a lack of holistic overview between different fire stations: "Debrief should be about the whole incident, not just one crew” [Fire Officer 7]. 


\section{DISCUSSION AND CONCLUSION}

The division of resistance into categories such as positive/negative fails to address a number of important points. Specifically, the notion of workarounds as distinct but related phenomena has received scant consideration in the literature. Additionally, single antecedent conditions have been attributed to specific resultant behaviours. These issues will be reviewed in turn.

Many authors have studied resistance but have failed to consider the resultant activity, or workaround, as a separate, distinct and subsequent phenomena (Prasad and Prasad, 2000, Rosenthal, 2004, Lapointe and Rivard, 2005); at best authors view deviation neutrally or as an indication of a poorly designed system (Markus, 1983, Mumford et al., 1978, Hirschheim and Newman, 1988). However, such deviation may also be regarded as a positive opportunity for change.

Drawing from the literature and using a deductive analytical approach (Miles and Huberman, 1994), we propose an initial conceptual framework that differentiates between compliance and various types of user resistance and workaround, this is presented graphically in figure 1. 


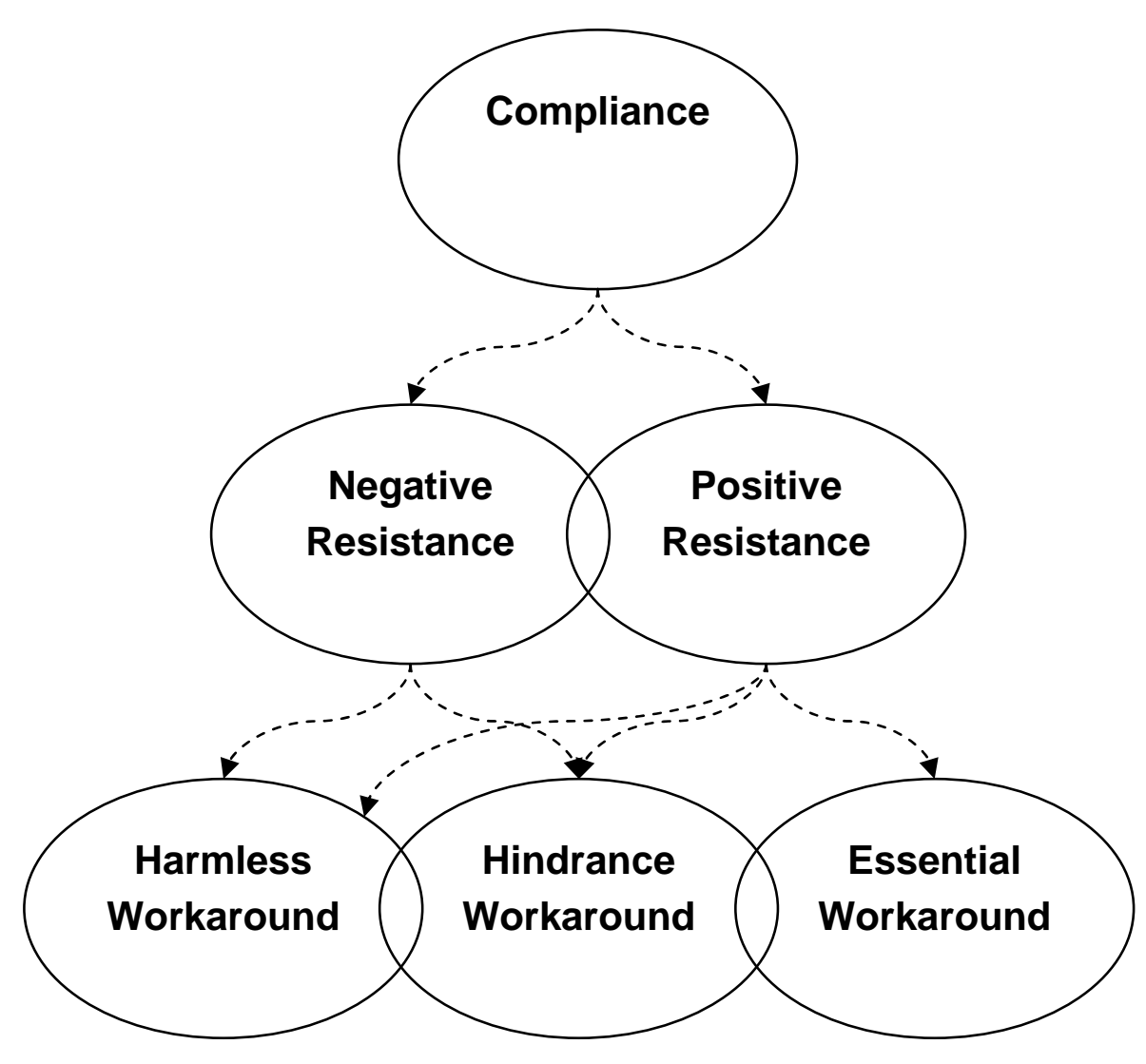

Figure 1: Initial Compliance/Resistance/Workaround Model

Figure 1 is a conceptual representation rather than a literal diagram hence no attempt should be made to assume a notion of 'degree', 'percentage' or 'proportion' of overlap of the various categories. We simply wish to depict that the categories are not exclusive and can be viewed from different perspectives. The figure is centred on the initial assumption of compliance; that the user will acquiesce to the system's prescribed function and form regardless of its effectiveness or suitability. However, we propose that a range of motives may move the user from compliance towards either positive or negative resistance, the intersection between positive and negative resistance illustrates that from the differing perspectives of various stakeholders an occurrence of resistance may be viewed positively or negatively (for example in the Fire Service case study the generation of an incident report giving a collective, mutually agreeable view of an incident was viewed as a positive act by Fire Service personnel who had 
been engaged in the incident, however from the management perspective such collective reports were viewed negatively as individual contributions were not attributable and became difficult to follow up).

Potential behaviours resulting from positive or negative resistance are defined as workaround activity. Specifically, three strands of workaround activity are proposed - harmless workarounds, hindrance workarounds and essential workarounds. The figure depicts harmless, hindrance and essential workarounds being potential behaviours resulting from positive resistance whilst only harmless and hindrance workarounds may result from negative resistance as, logically, a workaround can not be both essential and negative. Harmless workarounds are those which do not significantly affect workflow or data accuracy and can be the resultant action derived from either negative or positive resistance dependent on whether the motivation is to oppose or challenge the system or to enhance current working practices. Hindrance workarounds are subsequent actions where processes or procedures are avoided and can be the resultant action derived from either positive or negative resistance dependent on whether the hindrance was due to a poorly designed system, in which case the resistance activity can be regarded as positive, or whether the hindrance was burdensome for the operative, but a required action from the perspective of management or colleagues in which case the resistance activity can be regarded as negative. Finally, essential workarounds are necessary in order to complete the task at hand and can therefore be regarded as positive resistance actions, the presence of such essential workarounds may also highlight a dynamic organisational culture and willingness to innovate and improvise (Petrides et al, 2004).

The intersections of the workaround domains illustrate the notion of differing lenses. For example, in the harmless/hindrance workaround relationship, whilst from a management perspective the workarounds may be harmless as the information system's data integrity is maintained, from the user's perspective the system may be burdensome and hinder smooth 
working practice, hence from a user perspective a hindrance workaround is instigated. Again, viewed through a different lens, the rationale in the hindrance/essential workaround relationship, management may regarded deviation from set procedure as the workforce circumventing cumbersome processes whilst the workforce may regard such workarounds as essential in order to support their professional judgement and autonomy. Hence, rather than resistance or workaround behaviours existing in a fixed or static context there are many occasions when they may be viewed more dynamically and with differing positive or negative emphasis according to the organizational status and position, and individual perceptions, beliefs and attitudes of the particular witness.

Notably many accounts of essential workarounds take place in health studies (Wilson and Walsh, 1996, Wilson 2002, Timmons, 2003, Kobayashi et al., 2005) and similar issues were found in our Fire Service case study. Further research is required to examine common factors, but a brief overview would suggest that the emergency nature of activities, the critical and fast changing decisions that are made, and the dynamic interactions between agents appear difficult for an information system to support. If designers, developers and managers continue to view these workarounds as resistance, they are less likely to critically analyse their systems' designs or consider developing systems that are more adaptable, reconfigurable or accommodating both to allow them to be easily changed in light of positive, non-essential or harmless workarounds or more tightly controlled in the light of negative, hindering or evasive workarounds Indeed, information systems design is still suffering from lack of differentiation between representations of work and work in action, thus they are poorly designed for the dynamic reassessment of situations, altered plans or atypical independent or cooperative work (Suchman, 1987).

Revisiting previous models of resistance, single antecedent conditions are attributed to specific resultant resistant behaviours. For example, Joshi (1991) regards resistance as an 
outcome of gain or loss in equity status whilst Martinko et al., (1996) present a model that regards individual displays of resistance as dependent upon a user's or co-worker's previous experiences. However, as table 1 demonstrates, this work has identified four antecedent conditions: 'Enforced Proceduralisation', 'Organisational and Personnel Issues', 'Discipline' and 'Non-engagement with the System'. Our research reveals that these conditions can lead to resistance, be it positive or negative, which may result in different kinds of workaround behaviours. More specifically, a single antecedent condition can manifest in several resultant behaviours, in effect we propose a more dynamic model than has previously been considered.

\section{Conclusion}

In conclusion this study has re-examined the notion of resistance as reported in information systems literature and has utilised case study research to examine this further. As a result of the consolidation of both accepted literature and our own case study findings, we propose the new compliance/resistance/workaround model found in figure 1. This model identifies workarounds as a related but separate and distinct phenomenon from that of resistance. We argue that the concept of resistance may be better understood as a two phase process, the first phase being the internal individual/group cognitive or emotional process that results in the decision to resist, the second phase being the resultant workaround behaviour. We identify different types of resistance and workaround and, by portraying these as overlapping domains, show that these may often be perceived differently by individuals, groups, developers, management or organisations. The model should be regarded as a dynamic model as behaviours may be situated in different areas depending on the particular context of individual studies. 
Those studies that identify workarounds tend to regard such activity as temporary or exceptional, implying that workarounds exists only to solve a particular problem (Kobayashi et al, 2005; Wilson 2002, Petrides, 2004). This overlooks the fact that the problem may recur and that the dynamic artefacts used to solve it will be lost, together with the associated cognitive effort, for example, substitution of personnel or equipment in the face of lack of availability (Kobayashi et al., 2005, Button et al., 2003). If such exceptions are regular and similar actions need to be taken repeatedly, then ideally the supporting information system should dynamically evolve to incorporate them with the underlying rationale for workarounds being explored when considering future versions of systems. The limited studies on information systems workaround have focussed on the Health Service where, due to professional autonomy and the emergency nature of activities, workaround is perhaps unsurprising. Our studies have been at operator level in highly operationally controlled environments, where it might be expected that deviation from set procedure would be minimised, yet workaround has been shown to still exist. Specifically the workaround phenomena identified have been for more complex reasons than merely resistance, and we have studied this complexity by opening the 'black box' of resistance which has been seen historically as a reactive process accepting inputs in the form of changes to work-based systems and procedures and producing outputs in the form of attitudes and behaviours. By developing a composite model of user resistance/workaround we aim to further contribute to this understudied field and to suggest that it may be useful to all concerned with information systems development and implementation look deeper into the reasons why systems are not used as expected. 


\section{Acknowledgements}

The authors would like to thank the two anonymous reviewers for their valuable critiques and

suggestions. We are also indebted to the editors for their valuable advice and guidance.

\section{References}

Ansof, I. (1988) The New Corporate Strategy, New York, John Wiley \& Sons.

Bain, P. \& Taylor, P. (2000) Entrapped by the 'electronic panopticon'? Worker resistance in the call centre. New Technology, Work and Employment, 15, 2-18.

Button, G., Mason, D. \& Sharrock, W. (2003) Disempowerment and Resistance in the Print Industry? Reactions to Surveillance-Capable Technology. New Technology, Work and Employment, 18, 50-61.

Callaghan, G. \& Thompson, P. (2001) Edwards Revisited: Technical Control and Call Centres. Economic and Industrial Democracy, 22, 13-37.

Cook, S., D \& Brown, J., Seeley (1999) Bridging Epistemologies: The Generative Dance Between Organizational Knowledge and Organizational Knowing. Organization Science, 10, 381-400.

Davison, R. M., Martinsons, M. G. \& Kock, N. (2004) Principles of Canonical Action Research. Information Systems Journal, 14, 65-86.

Dourish, P., Holmes, J., MacLean, A., Marqvardsen, P. \& Zbyslaw, A. (1996) Freeflow: Mediating Between Representation and Action in Workflow Systems. Computer Supported Cooperative Work. ACM Press.

Eisenhardt, K. (1989) Building theory from case study research. Academy of Management Review, 14, 532-550.

Fernie, S. \& Metcalf, D. (1998) (Not) Hanging on the telephone: payment systems in the new sweatshops. Centre for Economic Performance, London School of Economics.

Folger \& Skarlicki (1999) Unfairness and Resistance to Change: Hardship as Mistreatment, Journal of Organisational Change Management, Vol.12, Issue 1, pp.35-50

Hirschheim, R. \& Klein, H., K. (1994) Realizing Emancipatory Principles in Information Systems Development: The Case for ETHICS. MIS Quarterly, 83-109.

Hirschheim, R. A. \& Newman, M. (1988) Information Systems and User Resistance: Theory and Practice. Computer Journal, 31, 398-408.

Jermier, J.M., Knights, D. and Nord, W. (Eds.) (1994) Resistance and Power in Organisations, London, Routledge

Joshi, K. (1991) A Model of Users' Perspective on Change: The Case of Information Systems Technology Implementation. MIS Quarterly, 15, 229-240.

Keen, P. (1981) Information Systems and Organisational Change. Communications of the ACM, 24.

Klein, H. K. \& Myers, M. D. (1999) A Set of Principles for Conducting and Evaluating Interpretive Field Studies in Information Systems. MIS Quarterly, 23, 67-94.

Kobayashi, I, M., Fussell, S. R., Xiao, Y. \& Seagull, F. J. (2005) work Co-ordination, Workflow, and Workarounds in a Medical Context. CHI 2005. Portland, Oregon, USA.

Kossek, E. E., Young, W., Gash, D. C. \& Nichol, V. (1994) Waiting for Innovation in the Human Resources Department: Godot Implements a Human Resource Information System. Human Resource Management, 33, 135-160.

Lankshear, G., Cook, P., Mason, D. \& Coates, S. (2001a) Call centre employees' responses to electronic monitoring: Some research findings. Work, Employment \& Society, 15, 595-605.

Lankshear, G. \& Mason, D. (2001) Technology and Ethical Dilemmas in a Medical Setting: Privacy, Professional Autonomy, Life and Death. Ethics and Information Technology, 3, 225-235.

Lankshear, G., Mason, D., Cook, P., Button, G. \& Coates, S. (2001) Call Centre Employees' Responses to Electronic Monitoring: Some Research Findings. Work Employment and Society. 
Lapointe, L. \& Rivard, S. (2005) A multilevel model of resistance to Information Technology Implementation. MIS Quarterly, 29, 461-491.

Lincoln, Y. S. \& Guba, E. G. (1985) Naturalistic Inquiry, Beverley Hills, Sage.

Lyytinen, K. \& Hirschheim, R. (1987) Information Systems failures, a Survey and Classification of the Empirical Literature. In: Oxford Surveys in Information Technology, 257-309

Marakas, G. \& Hornik, S. (1996) Passive Resistance misuse: overt support and covert recalcitrance in IS implementation. European Journal of Information Systems, 5, 208-219.

Markus, M., L. (1983) Power, Politics, and MIS Implementation. Communications of the ACM, 26, 430-444.

Martinko, M. J., Henry, J. W. \& Zmud, R. W. (1996) An Attributional Explanation of Individual Resistance to the Introduction of Information Technologies in the Workplace. Behaviour \& Information Technology, 15, 313-330.

Miles, M. \& Huberman, A. (1994) Qualitative Data Analysis: An Expanded Sourcebook, Thousand Oaks, CA, Sage.

Mumford, E., Land, F. F. \& Hawgood, J. (1978) A Participative Approach to Planning and Designing Computer Systems and Procedures to Assist This. Impact of Science on Society, 28, 235-253.

Orr, J. E. (1996) Talking about machines: An ethnography of a modern job, Ithaca, NY:ILR Press.

Prasad, P. \& Prasad, A. (2000) Stretching the Iron cage: The Constitution and Implications of Routine Workplace Resistance. Organization Science, 11, 387-403.

Petrides, L.A., McClelland, S.I. \& Nodine, T.R. (2004) Costs and Benefits of the Workaround: Inventive Solution or Costly Alternative. International Journal of Educational Management, 18:2, 100-108

Rosenthal, P. (2004) Management Control as an Employee Resource: The Case of Front-line Service Workers. Journal of Management Studies, 41, 601-622.

Schein, E. (1988) Organisational Psychology, Englewood Cliffs, NJ, Prentice Hall.

Sewell, G. \& Wilkinson, B. (1992) Someone to Watch Over Me: Surveillance, Discipline and the Justin-Time Labour Process. Sociology, 2, 271-289.

Sobreperez, P., Ferneley, E. H. \& Wilson, F. A. (2005) Tricks or Trompe L'oeil?: An examination of workplace resistance in an information rich managerial environment. ECIS: 13th European Conference on Information Systems. Regensburg, Germany.

Suchman, L. (1987) Plans and situated actions: The problem of human-machine communication, New York, Cambridge University Press.

Timmons, S. (2003) A failed panopticon: surveillance if nursing practice via new technology. New Technology, Work and Employment, 18, 143-153.

Waddell, D. \& Sohal, A. S. (1998) Resistance: A Constructive Tool for Change Management. Management Decision, 36, 543-548.

Walsham, G. (1993) Interpreting Information Systems in Organizations, Chichester, John Wiley \& Sons.

Webb, M. \& Palmer, G. (1998) Evading Surveillance and Making Time: an Ethnographic View of the Japanese Factory Floor in Britain. British Journal of Industrial Relations, 36, 611-627.

Wilson, T. \& Walsh, C. (1996) Information behaviour: An inter-disciplinary perspective. A report to the British Library Research \& Innovation Centre on a review of the literature.

Wilson, M. (2002) Rhetoric of Enrolment and Acts of Resistance: Information Technology as Text. In: Global and Organizational Discourse about Information Technology. Eds. Wynn, E.H, Whitley E.A, Myers M.D, DeGross J.I. Boston Massachusetts, Kluwer p 225-248

Wolcott, H. F. (1982) Differing styles of on-site research, or, "If it isn't ethnography, what is it?" The Review Journal of Philosophy and Social Science, 7, 154-169. 
Table 2: Antecedent Conditions and Resultant Behaviours Derived from the Case Studies

\begin{tabular}{|c|c|c|c|c|c|}
\hline \multirow{2}{*}{$\begin{array}{l}\text { Antecedent } \\
\text { Conditions }\end{array}$} & \multicolumn{2}{|c|}{ Resistance Rationale } & \multicolumn{3}{|c|}{ Resultant Behaviours } \\
\hline & Negative Resistance & Positive Resistance & Harmless Workaround & Hindrance Workaround & Essential Workaround \\
\hline \multirow{2}{*}{ 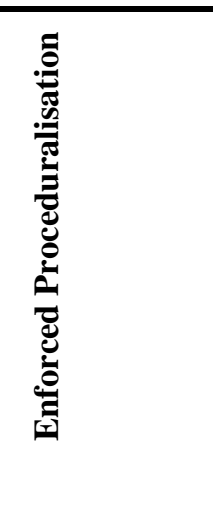 } & \multirow[t]{2}{*}{$\begin{array}{l}\text { Compliance of Superiors } \\
\text { Tacit knowledge and } \\
\text { acceptance of behaviours } \\
\text { by supervisors }\end{array}$} & $\begin{array}{l}\text { Avoidance of } \\
\text { inappropriate procedures } \\
\text { System offers inflexible or } \\
\text { unsuitable work sequence }\end{array}$ & $\begin{array}{l}\text { Incorrect Job Sequencing } \\
\text { Taking jobs out of sequence due } \\
\text { to resource availability } \\
\text { Sub Tasking } \\
\text { Subdivision of tasks into sub } \\
\text { tasks which are then performed } \\
\text { collectively }\end{array}$ & $\begin{array}{l}\text { Predictive Operating } \\
\text { Anticipating future } \\
\text { resource requirements }\end{array}$ & $\begin{array}{l}\text { Batch Processing } \\
\text { Collation of many multiple } \\
\text { tasks into a single task } \\
\text { Sub Tasking } \\
\text { Subdivision of tasks into sub } \\
\text { tasks which are then } \\
\text { performed collectively }\end{array}$ \\
\hline & & $\begin{array}{l}\text { Co-operative Working } \\
\text { Team and Intra- } \\
\text { organisational co-operation } \\
\text { not supported }\end{array}$ & & $\begin{array}{l}\text { Collective data } \\
\text { Generation } \\
\text { Collection of consensus } \\
\text { based data } \\
\text { Retrospective Data Entry } \\
\text { Entering data after the } \\
\text { event when recollection } \\
\text { may be inaccurate }\end{array}$ & $\begin{array}{l}\text { Collective data Generation } \\
\text { Collection of consensus } \\
\text { based data } \\
\text { Retrospective Data Entry } \\
\text { Entering data after the event } \\
\text { when recollection may be } \\
\text { inaccurate }\end{array}$ \\
\hline \multirow[b]{3}{*}{.气.: } & $\begin{array}{l}\text { Deception } \\
\text { Avoid or evade monitoring } \\
\text { and surveillance }\end{array}$ & & & $\begin{array}{l}\text { Inaccurate Data Entry } \\
\text { Entering of data that does } \\
\text { not accurately reflect } \\
\text { actual events }\end{array}$ & \\
\hline & $\begin{array}{l}\text { Inappropriate targets } \\
\text { Target too low or too high }\end{array}$ & & $\begin{array}{l}\text { Stockpiling } \\
\text { Ensuring targets are met early in } \\
\text { the day }\end{array}$ & $\begin{array}{l}\text { Stockpiling } \\
\text { Ensuring targets are met } \\
\text { early in the day }\end{array}$ & \\
\hline & $\begin{array}{l}\text { Personal and Social } \\
\text { Space } \\
\text { Gaining time to socialise } \\
\text { and relax }\end{array}$ & & $\begin{array}{l}\text { Buddying } \\
\text { Processing for others for } \\
\text { reasons of friendship } \\
\text { Bargaining } \\
\text { Processing for others to repay a } \\
\text { favour or balance workloads } \\
\text { Bullying } \\
\text { Processing for others under } \\
\text { coercion } \\
\text { Indolence } \\
\text { Avoidance of work }\end{array}$ & $\begin{array}{l}\text { Sabotage } \\
\text { System disruption or } \\
\text { stoppage through physical } \\
\text { damage } \\
\text { Indolence } \\
\text { Avoidance of work }\end{array}$ & \\
\hline 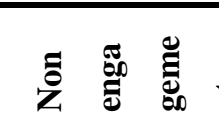 & $\begin{array}{l}\text { Deception } \\
\text { Avoid or evade monitoring } \\
\text { and surveillance }\end{array}$ & & & $\begin{array}{l}\text { Non-use of System } \\
\text { Systems not available or } \\
\text { bypassed altogether }\end{array}$ & \\
\hline
\end{tabular}




\begin{tabular}{|c|c|c|c|c|c|}
\hline \multirow{3}{*}{$\begin{array}{l}\text { Antecedent } \\
\text { Conditions }\end{array}$} & $\begin{array}{l}\text { Time Overhead } \\
\text { Avoid time wasted by } \\
\text { logging out and back in }\end{array}$ & & & $\begin{array}{l}\text { Buddying } \\
\text { Processing for others for } \\
\text { reasons of friendship } \\
\text { Bargaining } \\
\text { Processing for others to } \\
\text { repay a favour or balance } \\
\text { workloads } \\
\text { Bullying } \\
\text { Processing for others } \\
\text { under coercion } \\
\text { Indolence } \\
\text { Avoidance of work }\end{array}$ & \\
\hline & $\begin{array}{l}\text { Lack of Understanding } \\
\text { Lack of knowledge about } \\
\text { data requirements and } \\
\text { usage }\end{array}$ & \multirow[t]{2}{*}{$\begin{array}{l}\text { Lack of Understanding } \\
\text { Lack of knowledge about } \\
\text { data requirements and usage }\end{array}$} & & \multirow{2}{*}{$\begin{array}{l}\text { Inaccurate Data Entry } \\
\text { Entering of data that does } \\
\text { not accurately reflect } \\
\text { actual events }\end{array}$} & \\
\hline & $\begin{array}{l}\text { Compliance of Superiors } \\
\text { Tacit knowledge and } \\
\text { acceptance of behaviours } \\
\text { by supervisors }\end{array}$ & & & & \\
\hline \multirow{3}{*}{ 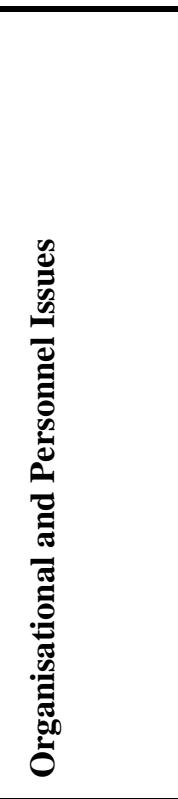 } & $\begin{array}{l}\text { Peer Pressure } \\
\text { Confidence and initiative } \\
\text { damage by peers }\end{array}$ & & & \begin{tabular}{|l} 
Inaccurate Data Entry \\
Entering of data that does \\
not accurately reflect \\
actual events
\end{tabular} & $\begin{array}{l}\text { Non-use of System } \\
\text { Systems not available or } \\
\text { bypassed altogether }\end{array}$ \\
\hline & & $\begin{array}{l}\text { Professional Judgement } \\
\text { Autonomy and discretion not } \\
\text { supported by mechanistic } \\
\text { recording and analysis of } \\
\text { data. }\end{array}$ & & $\begin{array}{l}\text { Retrospective Data Entry } \\
\text { Entering data after the } \\
\text { event when recollection } \\
\text { may be inaccurate }\end{array}$ & $\begin{array}{l}\text { Non-use of System } \\
\text { Systems not available or } \\
\text { bypassed altogether } \\
\text { Inaccurate Data Entry } \\
\text { Entering of data that does } \\
\text { not accurately reflect actual } \\
\text { events }\end{array}$ \\
\hline & & $\begin{array}{l}\text { Lack of Holistic Overview } \\
\text { Overview of situation not } \\
\text { supported or captured }\end{array}$ & & $\begin{array}{l}\text { Retrospective Data Entry } \\
\text { Entering data after the } \\
\text { event when recollection } \\
\text { may be inaccurate }\end{array}$ & \begin{tabular}{|l|} 
Non-use of System \\
Systems not available or \\
bypassed altogether \\
Inaccurate Data Entry \\
Entering of data that does \\
not accurately reflect actual \\
events
\end{tabular} \\
\hline
\end{tabular}

